\title{
Aflatoxin content and health risks associated with consumption of some herbal products sold in Kampala, Uganda
}

\author{
Patrick Onen $^{\text {a }}$, James Watmon ${ }^{\text {a }}$, Timothy Omara ${ }^{\text {b,c,d* }}$ Daniel Ocira $^{\text {a }}$ \\ ${ }^{a}$ Department of Chemistry, Faculty of Science, Kyambogo University, P. O. Box 1, Kyambogo, \\ Kampala, Uganda. \\ ${ }^{\mathrm{b}}$ Department of Chemistry and Biochemistry, School of Sciences and Aerospace Studies, Moi \\ University, Uasin Gishu County, P.O. Box 3900, Eldoret, Kenya. \\ ${ }^{c}$ Africa Center of Excellence II in Phytochemicals, Textiles and Renewable Energy (ACE II PTRE), \\ Moi University, Uasin Gishu County, P.O. Box 3900, Eldoret, Kenya. \\ ${ }^{\mathrm{d}}$ Department of Quality Control and Quality Assurance, Product Development Directory, \\ AgroWays Uganda Limited, Plot 34-60, Kyabazinga Way, P.O. Box 1924, Jinja, Uganda.
}

prof.timo2018@gmail.com,prof.timo2018@mu.ac.ke

Keywords: Aflatoxins, aflatoxicosis, estimated daily intake, hepatobiliary carcinoma, hazard index. Persuasive adverts and exaggeration of health benefits from consumption of herbal products as well as the mental picture of 'natural' is 'safe' has boosted traditional medicine use in Uganda. However, herbal products may be unsafe due to the possibility of their contamination with mycotoxins. In this study, we quantified the levels of aflatoxins $\left(\mathrm{B}_{1}, \mathrm{~B}_{2}, \mathrm{G}_{1}\right.$ and $\left.\mathrm{G}_{2}\right)$ in Real Koff product, Eddagala ly'e kifuba n'e senyiga, Omusujja, Cough mixture and Fever herbal products sold in Kampala, Uganda using high performance liquid chromatography-tandem mass spectrometry. The associated consumption health risks were assessed using the hazard index method. Only aflatoxin $\mathrm{B}_{1}$ was detected in $60 \%$ of the samples, with $40 \%$ of these surpassing WHO guidelines of $\leq 5 \mu \mathrm{g} / \mathrm{kg}$. The hazard indices were all less than 1, implying that Ugandans who heavily rely on the herbal products are exposed to aflatoxins at sublethal doses which may lead to chronic effects in the long run. Studies using a larger sample size should assess whether the current observation is a routine occurrence or a sporadic event.

\section{Introduction}

Plants have been known for their medicinal potential since antiquity [1]. They continue to be a veritable source of not less than $40 \%$ of the current therapeutically utilized products. Some studies have indicated that the use of herbal products to address health challenges could be unsafe due to the possibility of their contamination with heavy metals $[2,3]$, pesticide residues, and toxigenic fungi such as Aspergillus, Fusarium and Penicillium species during processing and packaging $[4,5]$. These fungi are 
known to produce potential mycotoxins (aflatoxins, fumonisins, ochratoxins, deoxynivalenol, zearalenone and T-2 toxins), which may have negative health impacts on humans [6].

Aflatoxins (AFs) is a group of secondary metabolites produced by fungi of the genus Aspergillus, majorly A. flavus and A. parasiticus. About 20 different types of AFs have been recognized. However, aflatoxin $\mathrm{B}_{1}\left(\mathrm{AFB}_{1}\right)$, aflatoxin $\mathrm{B}_{2}\left(\mathrm{AFB}_{2}\right)$, aflatoxin $\mathrm{G}_{1}\left(\mathrm{AFG}_{1}\right)$, aflatoxin $\mathrm{G}_{2}\left(\mathrm{AFG}_{2}\right)$, aflatoxin $\mathrm{M}_{1}\left(\mathrm{AFM}_{1}\right)$ and aflatoxin $\mathrm{M}_{2}\left(\mathrm{AFM}_{2}\right)$ are of utmost toxicological importance [7]. AFs have a wide occurrence in different matrices. They have been reported in agricultural foods including cereals (rice, maize, sorghum, millet), cassava, nuts, oil seeds (such as sesame, sunflower), meat, eggs, dairy products, spices and animal feeds [8]. In foods and herbal products, they may occur before, during or after harvest, during storage or processing under conditions that favour the survival of the producing Aspergillus fungi [9-11].

In our previous study [6], we concluded that various commodities in Uganda are contaminated with AFs, and most communities are exposed to acute chronic levels. Furthermore, we identified that herbal products, beers, barley and animal products (meat and blood) have been barely assessed in regard to these toxins. The aim of this study was therefore to quantify aflatoxins $\left(\mathrm{AFB}_{1}, \mathrm{AFB}_{2}, \mathrm{AFG}_{1}\right.$ and $\left.\mathrm{AFG}_{2}\right)$ in Real Koff, Eddagala ly'e kifuba n'e senyiga, Omusujja,
Cough mixture and Fever herbal products traded in Kampala city of Uganda and assess the probable human health risks from their consumption.

\section{Experimental part}

\section{Materials and methods}

Aflatoxin $\left(\mathrm{AFB}_{1}, \mathrm{AFG}_{1}, \mathrm{AFB}_{2}\right.$ and $\left.\mathrm{AFG}_{2}\right)$ standards were procured from Sigma (St. Louis, MO, USA). Ethanol, methanol, and acetonitrile were from Sigma (Sigma-Aldrich, Steinheim, Germany). All other reagents used were of analytical grade, supplied by Merck (Darmstadt, Germany) and Sigma (St. Louis, MO, USA).

\section{Sample collection and preparation}

Liquid dosage forms of five common herbal medicines in their original packaging were each obtained from 15 popular herbal shops in Kampala, Uganda on $15^{\text {th }}$ December 2019 (Table 1; Figure 1). Kampala was chosen because of the big market and high sale turnover of herbal medicines [12]. Selection of these herbal formulations was also based on their availability and affordability by the public following a pilot survey. Samples were analyzed at Directorate of Government Analytical Laboratory, Wandegeya, Kampala, Uganda.

Table 1. Liquid herbal medicines sampled from Kampala, Uganda.

\begin{tabular}{|c|c|c|}
\hline ID & Trade name & $\begin{array}{c}\text { Ailment(s) claimed to } \\
\text { treat }\end{array}$ \\
\hline SL1 & Real Koff product & Cough and flu \\
\hline SL2 & $\begin{array}{c}\text { Eddagala ly'e kifuba } \\
\text { n'e senyiga }\end{array}$ & Cough and flu \\
\hline SL3 & Omusujja & Various ailments \\
\hline SL4 & Cough mixture & $\begin{array}{c}\text { Cough, asthma, } \\
\text { fever, ulcers, measles }\end{array}$ \\
\hline SL5 & Fever & Fever \\
\hline
\end{tabular}




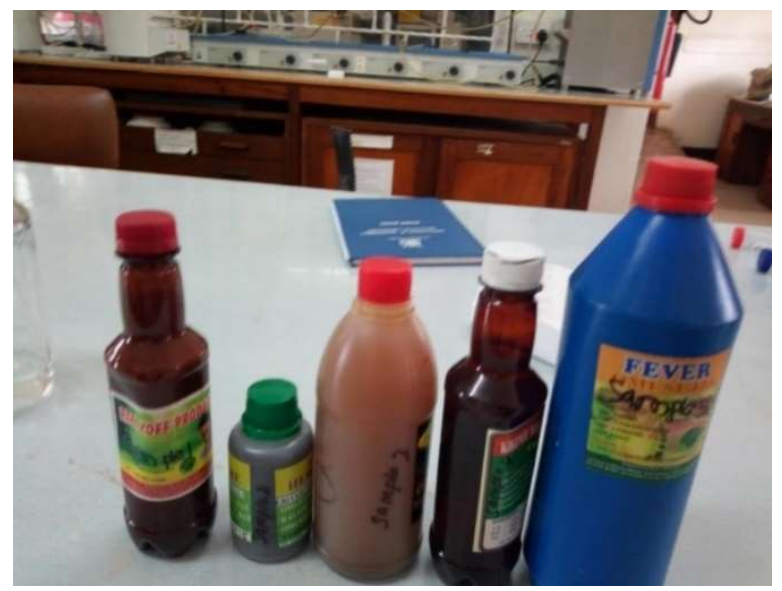

Figure 1. One set of the sampled herbal medicines in their original packaging (left to right: Real Koff product, Eddagala ly'e kifuba n'e senyiga, Omusujja, Cough mixture and Fever).

\section{Aflatoxin analysis}

The working standards for AFs: $125 \mu \mathrm{L}$ for $\mathrm{AFB}_{1}$ and $\mathrm{AFG}_{1}, 450 \mu \mathrm{L}$ for $\mathrm{AFB}_{2}$ and $\mathrm{AFG}_{2}$ were diluted to $5 \mathrm{~mL}$ with acetonitrile/water (50: 50 $\mathrm{v} / \mathrm{v}$ ) resulting in an intermediate mixed solution of $0.05 \mu \mathrm{g} / \mathrm{mL}$ for $\mathrm{AFB}_{1}$ and $\mathrm{AFG}_{1}, 0.047 \mu \mathrm{g} / \mathrm{mL}$ and $0.045 \mu \mathrm{g} / \mathrm{mL}$ for $\mathrm{AFB}_{2}$ and $\mathrm{AFG}_{2}$, respectively.

Aliquots $(30 \mathrm{ml})$ of each sample were extracted using $10 \mathrm{ml}$ acetonitrile-water (84: $16 \mathrm{v} / \mathrm{v})$ for 30 minutes with shaking at room temperature at 126 $\mathrm{rpm}$. They were then centrifuged for 5 minutes at $3000 \times$ g. Solid phase extraction was done and $0.4 \mathrm{ml}$ of the extracts were diluted with $0.6 \mathrm{ml}$ of ammonium formate in water.

Determination of aflatoxin levels in the sample extracts was performed by isocratic reversedphase high performance liquid chromatographytandem mass spectrometry with a MS/MS detector from Agilent Technologies (6400 Series Triple Quadrupole B.08.00, B8023.0). The analyses used binary gradient elution with solvent A (a mixture of $0.1 \%$ formic acid in water and $0.1 \%$ ammonium formate in water) while solvent $\mathrm{B}$ was made of $0.1 \%$ formic acid in methanol [13]. The total run time was 7 minutes.

Sample solutions of $5 \mu \mathrm{L}$ were injected into C-18 reverse phase column (Poroshell 120 EC-C18 3 $\times 50 \mathrm{~mm}, 2.7 \mu \mathrm{m}$, USA). Data acquisition software was for 6400 Series Triple Quadrupole, version B.08.00 while qualitative analysis software used was version B.07.00 Service Pack 1. The flow rate was set at $0.3 \mathrm{~mL} / \mathrm{min}$ and the column temperature maintained at $40.01{ }^{\circ} \mathrm{C}$. The ionization source of the MS/MS detector had 4.0 $\mathrm{kV}$ capillary voltage, $350{ }^{\circ} \mathrm{C}$ source temperature and $10 \mathrm{~mL} / \mathrm{min}$ desolvation gas flow using nitrogen gas (Supplementary File 1. Table $\mathrm{S} 1)[13]$.

The concentration of each aflatoxin in the samples were separately calculated by using the individual calibration curves obtained from the peak heights of each aflatoxin standard. Standards and samples were analyzed with a method detection limit of $0.03 \mu \mathrm{g} / \mathrm{kg}$.

Quality control was achieved through triplicate analysis of samples.

\section{Human health risk assessment}

The estimated daily intake (EDI) for ingestion of the herbal medicines as well as the hazard index (HI) were computed for both children (representing a sensitive group) and adults (representing the general population) to 
approximate probable exposure through intake of herbal medicines. This was because traders reiterated that most people believed in the herbal products and take them daily, some along with their children, as a measure of preventing the ailments.

The EDI was calculated using the mean levels of total aflatoxins obtained in the herbal medicines, the daily herbal intake of $0.25 \mathrm{~L} /$ day and 0.75 L/day for Ugandan children and adults respectively [14] and the mean body weights of $11.3 \mathrm{~kg}$ and $72.3 \mathrm{~kg} /$ person for children and adults respectively [15-17]. The EDI expressed in $\mathrm{ng} / \mathrm{kg}$ of the body-weight/day ( $\mathrm{ng} / \mathrm{kg}$ bw/day) was calculated using Equation 1 [17-19].

EDI $=\frac{\text { Daily intake of herbal medicine } \times \text { Mean level of aflatoxins }}{\text { Average body weight in Kg }}$

Where daily intake of herbal medicine is in L/day, mean level of aflatoxins in $\mathrm{ng} / \mathrm{kg}$ and average body weight in $\mathrm{kg}$.

The hazard index was determined by dividing the EDI by $\mathrm{TD}_{50}$ (the daily dose in $\mathrm{ng} / \mathrm{kg} / \mathrm{bw} /$ day at which $50 \%$ of test animals would have developed tumours), divided by a safety factor of 50,000 as described by previous authors [17, 19-21]. $\mathrm{TD}_{50}$ is the dose $(\mathrm{mg} / \mathrm{kg} / \mathrm{bw} / \mathrm{day})$ required to induce tumors in half of the test animals that would have remained tumor-free at zero dose. The complete mathematical relation of these parameters is given in Equation 2.

$$
\mathrm{HI}=\sum_{\mathrm{n}=0}^{i} \frac{\mathrm{EDI} / \mathrm{TD} 50}{50,000}
$$

\section{Statistical analysis}

All quantitative data, unless otherwise stated, were presented as means with errors represented by standard deviations attached. The analyses were done using Minitab statistical software (v17, Minitab Inc., USA). The aflatoxin content of the samples was compared with the acceptable levels of aflatoxins in herbal products recommended by World Health Organization, European and United States pharmacopeias.

\section{Results and Discussion}

Aflatoxin content of the herbal medicines The current study evaluated the aflatoxin content of some herbal products sold in Kampala (Uganda) using a combination of highperformance liquid chromatography and liquid chromatography-tandem quadrupole mass spectrometry. Despite the existence of several methods described for the determination of AFs in matrices [7], none of them can be applied to all matrices. In the case of natural products, the difficulty stems from the chemical complexity of different compounds in medicinal plants [22]. However, high-performance liquid chromatography-tandem quadrupole mass spectrometry (HPLC-MS/MS) has been reported and validated to determine the presence of AFs more accurately than HPLC and avoids the tedious derivatization process [23]. This method overcomes the drawbacks of HPLC by using tandem MS/MS detection, and is regarded as a confirmatory method for quick determination of $\mathrm{AFB}_{1}, \mathrm{AFB}_{2}, \mathrm{AFG}_{1}$ and $\mathrm{AFG}_{2}$ [23]. In this study, 
we did not revalidate this method as it was already validated in-house by the same laboratory which handles at least $50 \%$ of samples requiring $\mathrm{AFs}$ analyses from most parts of the country.

The aflatoxin content of the herbal products are given in Table 2. $\mathrm{AFB}_{1}$ was detected in $60 \%$ $(3 / 5)$ of the herbal products: Real Koff product, Omusujja and Fever with mean $\mathrm{AFB}_{1}$ levels of $6.83 \pm 0.04,6.38 \pm 0.03$ and $4.97 \pm 0.07 \mu \mathrm{g} / \mathrm{kg}$, respectively. Real Koff product and Omusujja had $\mathrm{AFB}_{1}$ in levels above WHO guideline, European pharmacopoeia as well as United States pharmacopoeia of $\leq 5, \leq 2$ and $\leq 5 \mu \mathrm{g} / \mathrm{kg}$, respectively. In a previous study, Odda et al. [11] reported that the shoot powder of Phyllanthus amarus (Schum. and Thonn) from Tororo (Uganda) were contaminated with AFs in levels above the recommended limits for total AFs by WHO. In the current study, it was found that among the four AFs, $\mathrm{AFB}_{1}$ was detected as the most common and only contaminant. This is in consonance with previous reports [22-24] in which $\mathrm{AFB}_{1}$ was the dominant contaminant. This is usually because A. flavus which produces $\mathrm{AFB}_{1}$ and $\mathrm{AFB}_{2}$ is a very common fungus which infect plants. Conversely, $\mathrm{AFG}_{1}$ and $\mathrm{AFG}_{2}$ are less often detected in plant products because the producing fungus (A. parasiticus) does not infect plants very often $[23,25,26]$. This may account for the high incidence and concentrations of $\mathrm{AFB}_{1}$ compared with $\mathrm{AFG}_{1}$ and $\mathrm{AFG}_{2}$ in the herbal products investigated in this study. In addition, the total absence of other AFs in herbal products have been reported before [23, 27, 28].

Table 2. Aflatoxin content of the sampled herbal medicines from Kampala, Uganda.

\begin{tabular}{|c|c|c|c|c|c|}
\hline \multirow{2}{*}{ Sample ID } & \multicolumn{5}{|c|}{ Aflatoxin concentration $(\mu \mathrm{g} / \mathrm{kg})$} \\
\cline { 2 - 6 } & $\mathrm{AFB}_{1}$ & $\mathrm{AFB}_{2}$ & $\mathrm{AFG}_{1}$ & $\mathrm{AFG}_{2}$ & $\begin{array}{c}\text { Total } \\
\mathrm{AFs}\end{array}$ \\
\hline $\mathrm{SL} 1$ & $6.83 \pm 0.04$ & $\mathrm{BDL}$ & $\mathrm{BDL}$ & $\mathrm{BDL}$ & 6.83 \\
\hline $\mathrm{SL} 2$ & $\mathrm{BDL}^{*}$ & $\mathrm{BDL}$ & $\mathrm{BDL}$ & $\mathrm{BDL}$ & $\mathrm{NA}$ \\
\hline $\mathrm{SL} 3$ & $6.38 \pm 0.03$ & $\mathrm{BDL}$ & $\mathrm{BDL}$ & $\mathrm{BDL}$ & 6.38 \\
\hline SL4 & $\mathrm{BDL}$ & $\mathrm{BDL}$ & $\mathrm{BDL}$ & $\mathrm{BDL}$ & $\mathrm{NA}$ \\
\hline SL5 & $4.97 \pm 0.07$ & $\mathrm{BDL}$ & $\mathrm{BDL}$ & $\mathrm{BDL}$ & 4.97 \\
\hline $\begin{array}{c}\text { WHO } \\
\text { guideline }\end{array}$ & $\leq 5$ & $\mathrm{NE}$ & $\mathrm{NE}$ & $\mathrm{NE}$ & $\mathrm{NE}$ \\
\hline $\begin{array}{c}\text { European } \\
\text { pharmacopeia }\end{array}$ & $\leq 2$ & $\mathrm{NE}$ & $\mathrm{NE}$ & $\mathrm{NE}$ & $\mathrm{NE}$ \\
\hline $\begin{array}{c}\text { US } \\
\text { pharmacopeia }\end{array}$ & $\leq 5$ & $\mathrm{NE}$ & $\mathrm{NE}$ & $\mathrm{NE}$ & $\mathrm{NE}$ \\
\hline
\end{tabular}

*BDL: Below method detection limit, ${ }^{* * N A}$ : Not applicable, NE: No established limit.

A plausible explanation for this observation could be due to the absence of the toxigenic fungi in the samples, the phytochemicals present in the products [29, 30] or environmental conditions during harvest and storage that did not favour biosynthesis of the other AFs. It is documented that temperature and water activity are the main factors that influence fungal invasion and the production of AFs in stored products. For example, Kulshrestha et al. [31] earlier reported that with a water activity below 0.81 , temperatures of $25 \pm 2{ }^{\circ} \mathrm{C}, 30 \pm 2^{\circ} \mathrm{C}$, and $40 \pm 2$ ${ }^{\circ} \mathrm{C}$, and water activity over 0.81 and temperature below $10 \pm 2{ }^{\circ} \mathrm{C}$, AFs were not detected in medicinal products that contained A. flavus (an aflatoxin producer). Similar results were later reported in Italy with no AFs detected in 48 infusions and medicinal plants analyzed [28]. 
Though $40 \%$ and $10 \%$ of the samples had undetectable and allowable aflatoxin levels in herbal products, it should be noted that low level intake of AFs over long periods result in chronic aflatoxicosis expressed as impaired food conversion, stunting in children, immunosuppression, cancer and reduced life expectancy [32-35].

\section{Human exposure assessment}

The estimated daily intakes of the herbal medicines ranged from $5.61 \times 10^{-2} \mu \mathrm{g} / \mathrm{kg} / \mathrm{bw} /$ day to $1.51 \times 10^{-1} \mu \mathrm{g} / \mathrm{kg} / \mathrm{bw} /$ day for both Ugandan children and adults (Table 3 ).

Table 3. Human health risk assessment for Ugandans via intake of the herbal medicines.

\begin{tabular}{|c|c|c|c|}
\hline Index & Sample & Children & Adults \\
\hline \multirow{5}{*}{ 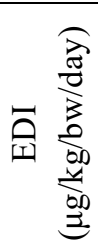 } & SL1 & $1.51 \times 10^{-1}$ & $7.09 \times 10^{-2}$ \\
\hline & SL2 & Not applicable & Not applicable \\
\hline & SL3 & $1.41 \times 10^{-2}$ & $6.62 \times 10^{-2}$ \\
\hline & SL4 & Not applicable & Not applicable \\
\hline & SL5 & $1.09 \times 10^{-1}$ & $5.16 \times 10^{-2}$ \\
\hline \multirow{5}{*}{ 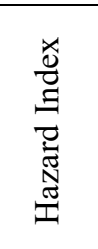 } & SL1 & $2.32 \times 10^{-6}$ & $1.09 \times 10^{-6}$ \\
\hline & SL2 & Not applicable & Not applicable \\
\hline & SL3 & $2.17 \times 10^{-6}$ & $1.02 \times 10^{-6}$ \\
\hline & SL4 & Not applicable & Not applicable \\
\hline & SL5 & $1.69 \times 10^{-6}$ & $7.93 \times 10^{-7}$ \\
\hline
\end{tabular}

The recorded hazard indices were in the range of $7.93 \times 10^{-7}$ to $2.32 \times 10^{-6}$. Hazard indices less than or equal to 1 indicates no significant health risk but the possibility of longterm adverse health effects increases with increasing hazard index. Hazard index between 1.1 and 10 reflects a moderate risk while hazard index greater than 10 indicates high risk [17]. The computed hazard indices were all less than 1, implying that daily consumption of the individual herbal products may not pose health risks. However, the risk is higher in children. This is due to their higher dietary exposure per $\mathrm{kg}$ body weight and the differences in their body physiology when compared to adults [36]. The risks may also be amplified if two or more of the herbal products are consumed in tandem.

\section{Conclusions}

In the current study, we found that three out of the five commonly used herbal medicines in Kampala, Uganda were contaminated with aflatoxin $\mathrm{B}_{1}$, a potent carcinogen. Thus, Ugandans who heavily rely on herbal products could be exposed to aflatoxins at sublethal doses, which could have long term carcinogenic effects. We recommend further studies using a large sample size and in other parts of Uganda. The mycoflora associated with the contamination as well as co-ocurrence of aflatoxins with other mycotoxins in Ugandan herbal products should be investigated.

\section{Acknowledgements}

The authors are grateful to Directorate of Government analytical laboratory, Kampala, Uganda for the analytical services which made this research a success.

\section{References}

[1] Goldstein LH, Elias M, Ron-Avraham G, et al. Consumption of herbal remedies and dietary supplements amongst patients hospitalized in medical wards. Br J Clin Pharmacol. 2007; 64:373-380. 
[2] Abdulla NM, Adam B, Blair I, Oulhaj A. Heavy metal content of herbal health supplement products in Dubai - UAE: a cross-sectional study. BMC Complement Altern Med. 2019;19:276.

[3] Ssempijja F, Kasozi IK, Daniel Eze E, et al. Consumption of Raw Herbal Medicines Is Associated with Major Public Health Risks amongst Ugandans. J Environ Public Health. 2020;2020:8516105.

[4] Keter L, Too R, Mwikwabe N, et al. Risk of Fungi Associated with Aflatoxin and Fumonisin in Medicinal Herbal Products in the Kenyan Market. Sci World J. 2017; 2017:1892972.

[5] Ałtyn I, Twaruzek M. Mycotoxin contamination concerns of herbs and medicinal plants. Toxins. 2020; $12: 182$.

[6] Omara T, Nassazi W, Omute T, Awath A, et al. Aflatoxins in Uganda: An Encyclopedic Review of the Etiology, Epidemiology, Detection, Quantification, Exposure Assessment, Reduction, and Control. Int $\mathrm{J}$ Microbiol. 2020;2020:4723612.

[7] Wacoo AP, Wendiro D, Vuzi PC, Hawumba JF. Methods for detection of aflatoxins in agricultural food crops. J Appl Chem. 2014; 2014: 706291.

[8] Marchese S, Polo A, Ariano A, Velotto S, Costantini S, Severino L. Aflatoxin B1 and M1: Biological Properties and Their Involvement in Cancer Development. Toxins. 2018;10:214.

[9] Bbosa GS, Kitya D, Odda J, Ogwal-Okeng J. Aflatoxins metabolism, effects on epigenetic mechanisms and their role in carcinogenesis. Health. 2013; 5:14-34.

[10] Bennett JW, Klich M. Mycotoxins. Clin Microbiol Rev. 2003;16:497-516.

[11] Odda J, Aliero AA, Waako P, Obua C, Kabasa JD. Microbiological analysis and total aflatoxins levels from shoot powder of Phyllanthus amarus (Schum. and Thonn) from Tororo, Uganda. Novel Res Microbiol J. 2018; 2:7584.

[12] Segawa N. Traditional healers don't want their herbs regulated, citing risk to intellectual property. 2019. Retrieved from https://globalpressjournal.com/africa/uganda/ugandanbill-regulate-herbs-met-mistrust-traditional-healers/.

[13] Nakhjavan B, Ahmed NS, Khosravifard M. Development of an Improved Method of Sample Extraction and Quantitation of Multi-Mycotoxin in Feed by LC-MS/MS. Toxins. 2020; 12: 462.

[14] Katuura E, Omujal F, Tumusiime RH, Nabukalu D, Byamukama R. Documentation of indigenous knowledge on medicinal plants used to manage common influenza and related symptoms in Luwero district, central Uganda. J Med Plants Res. 2016; 10: 705-716.

[15] Ralston ME, Myatt MA. Weight estimation tool for children aged 6 to 59 months in limited-resource settings. PLoS One. 2016; 11:e0159260.

[16] Kirunda BE. Body Weight and Physical Activity of Adults in Rural Uganda. PhD Thesis, University of Bergen, Norway. 2017. http://bora.uib.no/bitstream/handle/1956/16414/drthesis2017-Barbara-Eva-

Kiruna.pdf? sequence $=4 \&$ is Allowed $=\mathrm{y}$.

[17] Echodu R, Maxwell Malinga G, Moriku Kaducu J, Ovuga E, Haesaert G. Prevalence of aflatoxin, ochratoxin and deoxynivalenol in cereal grains in northern Uganda: Implication for food safety and health. Toxicol Rep. 2019;6:1012-1017.

[18] dos Santos JS, Souza TM, Ono EYS, Hashimoto $\mathrm{EH}$, et al. Natural occurrence of deoxynivalenol in wheat from Paraná State, Brazil and estimated daily intake by wheat products. Food Chem. 2013;138: 90-95.

[19] Taghizadeh SF, Rezaee R, Davarynejad G, et al. Risk assessment of exposure to aflatoxin B1 and ochratoxin A through consumption of different Pistachio (Pistacia vera L.) cultivars collected from four geographical regions of Iran. Environ Toxicol Pharmacol. 2018;61:61-66.

[20] Ishikawa AT, Takabayashi-Yamashita CR, Ono EY, et al. Exposure Assessment of Infants to Aflatoxin $M_{1}$ through Consumption of Breast Milk and Infant Powdered Milk in Brazil. Toxins. 2016;8:246. 
[21] Ismail A, Riaz M, Levin RE, Akthhar S, et al. Seasonal prevalence level of aflatoxin $M 1$ and its estimated daily intake in Pakistan. Food Control. 2016; 60: 461-465.

[22] Prado G, Guilherme A, Aline F, Gomes TCB, Leal AS, Morais VAD, et al. Occurrence of Aflatoxin B1 in natural products. Braz J Microbiol. 2012; 43: 1428-1435

[23] Siddique NA, Mujeeb M, Ahmad S, Panda BP, Makhmoor M. Determination of aflatoxins in medicinal plants by high-performance liquid chromatographytandem mass spectrometry. J Pharm Pharm Sci. 2013;16:321-330.

[24] Ezekwesili-Ofili J, Onyemelukwe N, Agwaga P, Orji I. The bioload and aflatoxin content of herbal medicines from selected states in Nigeria. Afr J Tradit Complement Altern Med. 2014;11:143-147.

[25] Dorner JW, Richard JC, Diener UL. The relationship of Aspergillus flavus and A. parasiticus with reference to production of aflatoxins and cyclopiasonic acid. Mycopathologia. 1984; 87:13-15.

[26] Abeywickrama E, Bean GA. Toxigenic Aspergillus flavus and aflatoxins in Sri Lankan medicinal plant material. Mycopathologia. 1991; 113: 187-190.

[27] Katerere DR, Stockenström S, Thembo KM, Rheeder JP, et al. A Preliminary Survey of Mycological and Fumonisin and Aflatoxin Contamination of African Traditional Herbal Medicines Sold in South Africa. Human Experiment Toxicol. 2008; 27 : 793-98.

[28] Romagnoli B, Menna V, Gruppioni N, Bergamini C. Aflatoxins in spices, aromatic herbs, herb-teas and medicinal plants marketed in Italy. Food Control. 2007; 18: 697-701.

[29] Zhou W, Hu L-B, Zhao Y, Wang M-Y, Zhang H, Mo H-Z. Inhibition of fungal aflatoxin B1 biosynthesis by diverse botanically derived polyphenols. Trop J Pharm Res 2015. 14: 605-609.

[30] Tiwari S, Shankar J. Integrated proteome and HPLC analysis revealed quercetin-mediated inhibition of aflatoxin B1 biosynthesis in Aspergillus flavus. 3 Biotech. 2018; 8:1-11.
[31] Kulshrestha R, Gupta CP, Shukla G, Kundu MG, Bhatnagar SP, Katiyar CK. The effect of water activity and storage temperature on the growth of Aspergillus flavus in medicinal herbs. Planta Med. 2008;74:1308-1315.

[32] Omara T, Kiprop AK, Wangila P, Wacoo AP, et al. The Scourge of Aflatoxins in Kenya: A 60-Year Review (1960 to 2020). J Food Qual. 2021; 2021: 8899839.

[33] Williams JH, Phillips TD, Jolly PE, Stiles JK, Jolly CM, Aggarwal D. Human aflatoxicosis in developing countries: a review of toxicology, exposure, potential health consequences, and interventions. Am J Clin Nutr. 2004;80:1106-1122.

[34] Cardwell KF, Henry SH. Risk of exposure to and mitigation of effect of aflatoxin on human health: a West African example. Toxin Rev. 2004; 23:217-247.

[35] Farombi EO. Aflatoxin contamination of foods in developing countries: implications for hepatocellular carcinomaand chemopreventive strategies. Afr J Biotechnol. 2006; 5:1-14.

[36] Huong BTM, Tuyen LD, Madsen H, Brimer L, Friis H, Dalsgaard A. Total Dietary Intake and Health Risks Associated with Exposure to Aflatoxin B1, Ochratoxin A and Fuminisins of Children in Lao Cai Province, Vietnam. Toxins. 2019;11:638. 